\title{
REFLEXÃO SOBRE A INCLUSÃO DO SURDO NO MERCADO DE TRABALHO
}

\author{
Reflection on the inclusion of the deaf in the labor market
}

\author{
Maria de Fátima Nunes Antunes - Univates/Brasil \\ Inedio Arcari - UNEMAT/Brasil \\ Marcelo Máximo Purificação - Docente Adjunto no Centro Universitário de Mineiros \\ (UNIFIMES), Brasil.
}

\begin{abstract}
RESUMO: Esse artigo tem como finalidade evidenciar o preconceito e as dificuldades de inserção do surdo no mercado de trabalho. Uma das grandes questões a serem refletidas é o detalhamento desse paradigma histórico de barreiras na vida profissional das pessoas surdas, que têm sofrido com as limitações da inclusão nos diferentes campos da sociedade. Portanto, o objetivo principal do presente estudo é discutir a problemática da inserção do surdo no mercado de trabalho e o método abordado para o desenvolver foi o relato de convivência com pessoas não ouvintes que nele atuavam. A pesquisa mostra que o cumprimento da Lei 10436/2002 (LIBRAS) está distante de se tornar uma realidade, apontando que os indivíduos que trabalham com os surdos não conseguem se comunicar em Libras, o que consiste em um regresso e contribui para a redução do profissionalismo do surdo. Nesse sentido, o estudo propõe, além de difundir o tema na sociedade, conscientizá-la do problema e, consequentemente, possibilitar a redução dessas dificuldades e preconceitos enfrentados por essa parcela da população.
\end{abstract}

Palavras-chave: Mercado de trabalho. Libras. Inclusão.

ABSTRACT: This article aims to show the prejudice and difficulties of insertion of the deaf to enter the labor market. One of the great issues to be reflected through this work is the detailing of this historical paradigm of barriers in the professional life of deaf people who, for many years, have been suffering from the limitations of inclusion in the different fields of society. Having as main objective the reflection about the problem of the inclusion of the deaf in the labor market, the method approached for the accomplishment of this work was thereport of coexistence with people with deafness who work in the job market, the research shows that the fulfillment of the law 10436/2002 (Pounds), is far from being a reality, pointing out that people working with the deaf can't communicate in Libras, leading to a return and reducing the professionalism of the deaf. Faced with this problem, the study proposes that the theme be disseminated by society so that there is awareness and that it becomes possible to contribute to reducing these difficulties and prejudices faced by the deaf.

Keywords: Labor market. Pounds. Inclusion.

\section{INTRODUÇÃO}

A proposta deste artigo é ampliar a discussão sobre o profissional surdo, evidenciando como é incluído e visto pela sociedade em geral e, por quem, muitas vezes, é discriminado. A história revela que a trajetória dos indivíduos não ouvintes é marcada

Educação, Psicologia e Interfaces, Volume 4, Número 3, p. 1-11, Outubro/Dezembro, 2020.

ISSN: 2594-5343.

DOI:https://doi.org/10.37444/issn-2594-5343.v4i3.325 
por imposições, experimentos sem sucesso, enfim, desconsideração social. Os surdos precisam utilizar a sua linguagem, mas, para que isso aconteça e vivam em igualdade com os ouvintes, precisam ser aceitos como são. Dessa forma, poderão interagir e demonstrar sua capacidade de pensar e aprender, buscando recursos para se habilitar ao mercado de trabalho, que é um direito de toda pessoa, seja ela deficiente ou não.

Esse tema nos possibilita ampliar a discussão, apontando dificuldades enfrentadas pelo surdo no meio social. O entendimento do contexto possibilita refletir sobre a necessidade do exercício da cidadania na promoção da inclusão. Nesse sentido, podemos contribuir para a inserção deste público-alvo da inclusão no mercado de trabalho, pois são notórios os desafios que o surdo tem enfrentado, mesmo com a existência de várias tecnologias que favorecem seu aprendizado e, assim, estender horizontes para a sua vida social e profissional.

Neste momento, é oportuno considerar que, não raro, o surdo tem superado as próprias expectativas ao conquistar seu espaço e crescer profissionalmente. Por outro lado, cabe lembrar que ainda há uma grande falta de interesse entre os que compõem o mercado de trabalho, que excluem a pessoa com deficiência embora ela esteja apta para aprender e utilizar os meios à sua disposição.

A deficiência auditiva é uma expressão usada para indicar a perda total ou parcial da audição, que, segundo decreto $\mathrm{n}^{\circ} 3.298$, de 20 de dezembro de 1999, é bilateral, parcial ou total, de quarenta e um decibéis $(\mathrm{dB})$ ou mais, aferida por audiograma nas frequências de $500 \mathrm{HZ}, 1.000 \mathrm{HZ}, 2.000 \mathrm{~Hz}$ e $3.000 \mathrm{~Hz}$.Também é possível classificá-la em decibéis que é organizada da seguinte maneira:

Normal - 0 a 25 dB - Audição Normal; Surdez Leve - 26 a $40 \mathrm{~dB}$ Existe alguma dificuldade para ouvir e entender conversação suave, obtendo melhores resultados em ambientes silenciosos e com vozes claras. A criança adquire $\mathrm{e}$ desenvolve a linguagem oral espontaneamente; Surdez Moderada - 41 a 70 dB - Dificuldade em entender uma conversação normal particularmente na presença de ruídos de fundo. A fala e o desenvolvimento da linguagem são geralmente afetados. Aparelhos auditivos podem ajudar a quase totalidade das dificuldades. Normalmente a criança apresenta alterações articulatórias por não perceber todos os sons com clareza. São crianças desatentas e com certa dificuldade no aprendizado da leitura e da escrita; Surdez Severa - 71 a $90 \mathrm{~dB}$ - a criança terá muita dificuldade no desenvolvimento espontâneo da fala, normalmente adquirem vocabulário do contexto familiar. Aparelhos auditivos são essenciais; Surdez Profunda $-+90 \mathrm{~dB}-$ Pode ouvir alguns sons em alto volume,

Educação, Psicologia e Interfaces, Volume 4, Número 4, p. 1-11, Outubro/Dezembro, 2020.

ISSN: 2594-5343. DOI: https://doi.org/10.37444/issn-2594-5343.v4i3.325 
porém percebe mais vibrações do que padrões tonais. Aparelhos auditivos ajudam de maneira limitada. A criança não consegue desenvolver a linguagem oral espontaneamente. Pode utilizar a leitura orofacial (SILVEIRA; NASCIMENTO, 2013, p. 105).

A deficiência ainda pode ser categorizada como surdez unilateral quando atinge apenas um ouvido; bilateral se acometer os dois. São vários os fatores que levam à perda da audição, como por exemplo, algum problema relacionado à determinada parte do ouvido. Segundo Silveira e Nascimento (2013, p. 106), as deficiências auditivas podem ser classificadas como:

Condutiva: é causada por um problema localizado na orelha externa e/ou média, que tem por função conduzir o som até a orelha interna. Em alguns casos, está deficiência é reversível e geralmente não necessita de aparelhos auditivos, somente tratamento médico e/ou cirúrgico. Neurosensorial: ocorre na orelha interna. Consiste numa diminuição na capacidade de receber os sons que passam pela orelha externa e média. Esta deficiência faz com que os indivíduos escutem menos e sintam maior dificuldade de perceber os sons. MISTA: ocorre quando a alteração auditiva está localizada na orelha externa e/ou média e orelha interna. Geralmente acontece devido a fatores genéticos, determinantes de má formação.

Central, disfunção auditiva central ou surdez central: este tipo de deficiência auditiva não é, necessariamente, acompanhado de diminuição da sensitividade auditiva, mas manifesta-se por diferentes graus de dificuldade na compreensão das informações sonoras. Decorre de alterações nos mecanismos de processamento da informação sonora no tronco cerebral (Sistema Nervoso Central).

Diversas são as conceituações quando se trata da importância da inclusão de pessoas com algum tipo de deficiência no mercado de trabalho. Assim, a deficiência auditiva segundo Fonseca (2017, s/p):

[...] é o nome usado para indicar perda de audição ou diminuição na capacidade de escutar os sons. Qualquer problema que ocorra em alguma das partes do ouvido pode levar a uma deficiência na audição. Entre as várias deficiências auditivas existentes, há as que podem ser classificadas como condutiva, mista ou neurossensorial. A condutiva é causada por um problema localizado no ouvido externo e/ou médio, que tem por função "conduzir" o som até o ouvido interno.

Este artigo trará uma reflexão sobre a problemática da inclusão do surdo no mercado de trabalho e, especificamente, analisará os preconceitos por ele enfrentados nesse contexto. Além disto, buscará compreender as dificuldades de acordo com a classificação da deficiência auditiva e analisar a importância do trabalho Bilíngue na

Educação, Psicologia e Interfaces, Volume 4, Número 3, p. 1-11, Outubro/Dezembro, 2020.

ISSN: 2594-5343. DOI:https://doi.org/10.37444/issn-2594-5343.v4i3.325 
prática pedagógica para a inserção no campo de trabalho. Este estudo se justifica pelo fato do tema ser pouco difundido, o que pode causar consequências negativas ao grupo em questão que, diariamente, enfrenta várias dificuldades e preconceitos que passam despercebidos pela sociedade de forma geral. Logo, com essa ideia, espera-se despertar a conscientização dessa sociedade visando minimizar esses preconceitos e limitações impostas aos indivíduos com problemas de audição.

\section{O PRECONCEITO NO MERCADO DE TRABALHO ENFRENTADO PELAS PESSOAS COM DEFICIÊNCIA AUDITIVA}

Historicamente, o preconceito que atinge pessoas com alguma deficiência - física, mental, auditiva, de visão, entre outras - tem sido um tema pouco discutido pela sociedade. Em efeito, esse problema, além de impor dificuldades de inserção no mercado de trabalho, afeta a vida social e familiar desses indivíduos. Sabemos que as limitações de cada ser humano podem ser conduzidas de forma a aportar para uma melhor qualidade de vida, bem-estar e convívio social. Caso contrário, o preconceito pode se tornar uma atitude corriqueira, levando as pessoas com alguma limitação a se sentirem incapazes de realizar atividades laborais e, consequentemente, a dependerem financeiramente de suas famílias, além de enfrentarem entraves sociais. De acordo com os dados do Instituto Brasileiro de Geografia e Estatística (IBGE):

[...] 6,2\% da população brasileira tem algum tipo de deficiência [..]. As pessoas com deficiência auditiva representam $1,1 \%$ da população brasileira, e esse tipo de deficiência foi o único que apresentou resultados estatisticamente diferenciados por cor ou raça, sendo mais comum em pessoas brancas $(1,4 \%)$, do que em negros $(0,9 \%)$. Cerca de $0,9 \%$ dos brasileiros ficaram surdos em decorrência de alguma doença ou acidente e $0,2 \%$ nasceu surdo. Do total de deficientes auditivos, $21 \%$ têm grau intenso ou muito intenso de limitações, o que compromete atividades habituais (VILELA, 2015, s/p.).

Uma das grandes dificuldades enfrentadas pelos não ouvintes no mercado de trabalho diz respeito à comunicação. Para minimizá-las, seria necessário que as pessoas atuantes em espaços empresariais dominassem a Língua em Libras, tornando, assim, a convivência entre ouvintes e surdos mais aprazível e as atividades mais produtivas. No entanto, esse contexto não se configura nos locais de trabalho. Esse tipo de barreira dificulta o acesso dessa população às vagas oferecidas pelas empresas, embora existam 
tentativas de amenizar o problema, como a Lei de Cotas e a Lei 8.213 de 24 de julho 1991, prevendo que:
A empresa com 100 (cem) ou mais empregados está obrigada a preencher de $2 \%$ (dois por cento) a $5 \%$ (cinco por cento) dos seus cargos com beneficiários reabilitados ou pessoas portadoras de deficiência, habilitadas, na seguinte proporção:
I - até 200 empregados....................................................................
II - de 201 a 500......................................................................

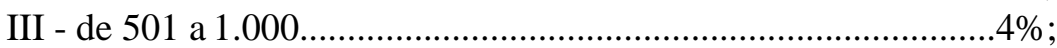

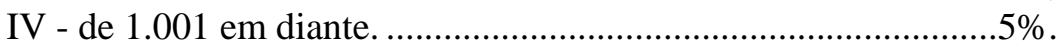

Mesmo assim, o índice de surdos inseridos no mercado de trabalho é pequeno, pois muitas empresas ainda não estão preparadas para receber pessoas com deficiência. O fato é demonstrado nos dados oficiais, que apontam que:

[...] a inclusão, para essas empresas, passa a ser um compromisso e um dos itens de sua política de responsabilidade social. Para tanto desenvolve um programa amplo, estruturado, de capacitação, recrutamento, seleção, contratação e desenvolvimento das pessoas portadoras de deficiência. Muitas empresas já entenderam que a inclusão das pessoas com deficiência é um grande aprendizado para o desenvolvimento de políticas de promoção e respeito à diversidade no ambiente de trabalho (BRASIL, 2007, p. 54).

Nesse sentido, já existem cursos voltados à preparação de surdos para exercerem funções no mercado de trabalho. Dessa forma, podem melhorar suas perspectivas de inclusão, como por exemplo, na multimídia, trazendo-lhes, novos horizontes sociais. O grande incentivo desses cursos são os benefícios proporcionados à sociedade, formando professores intérpretes, carreira que pode surgir a partir do treinamento de pessoas com deficiência auditiva. $\mathrm{O}$ fato contribui para a queda do paradigma social de que o surdo é um simples deficiente com incapacidades, passando a considerar suas escolhas profissionais. Vale lembrar que o Brasil reconheceu a Língua Brasileira de Sinais por meio da Lei $\mathrm{n}^{\circ} 10.436 / 2002$, cujo artigo $4^{\circ}$ apregoa que:

O sistema educacional federal e os sistemas educacionais estaduais, municipais e do Distrito Federal devem garantir a inclusão nos cursos de formação de Educação Especial, de Fonoaudiologia e de Magistério, em seus níveis médios e superiores, do ensino da Língua Brasileira de Sinais - Libras, como parte integrante dos Parâmetros Curriculares Nacionais - PCNs, conforme legislação vigente.

Educação, Psicologia e Interfaces, Volume 4, Número 3, p. 1-11, Outubro/Dezembro, 2020.

ISSN: 2594-5343. DOI:https://doi.org/10.37444/issn-2594-5343.v4i3.325 
Iniciativas como essa visam excluir a discriminação e inserir socialmente na sociedade todas as pessoas, inclusive as que apresentam algum tipo de deficiência, além de auxiliar na redução do preconceito nas mais diversas esferas, como nas salas de aula. Em efeito, os alunos devem ser educados com preceitos éticos e favoráveis ao convívio da diversidade, seja de cor, etnia, raça, religião e limitações físicas, entre outros. Sobre esse assunto, a convenção interamericana para eliminação de todas as formas de discriminação do Ordenamento Jurídico brasileiro, por meio do Decreto no 3956, de 8 de outubro de 2001, expressa que:

[...] as pessoas portadoras de deficiência têm os mesmos direitos humanos e liberdades fundamentais que outras pessoas e que estes direitos, inclusive o direito de não ser submetidas a descriminação com base na deficiência, emanam na dignidade e da igualdade que são inerentes a todo ser humano.

A imposição de barreiras aos surdos está em todos os âmbitos e pode ser percebida em vários setores. Isso inclui a educação quando se trata da Língua Brasileira de Sinais, pois existem poucos profissionais com essa habilidade de comunicação, o que acarreta empecilhos a tudo o que envolve a surdez, principalmente a forma de interagir com os sujeitos não ouvintes. Ademais, produz impacto no campo de trabalho tanto para as pessoas com deficiência, que, por obterem uma formação limitada, faz-se necessária a construção de projetos educacionais para atender às suas necessidades, como aos profissionais da educação não surdos para que, em maior número possível, possam aprender essa língua para se comunicar com o surdo. Segundo Ferreira et al. (2010, p. $74)$,

\footnotetext{
Para que a criança surda alcance o seu desenvolvimento total, a inclusão necessita de acompanhamento adequado, deve-se considerar a capacitação dos professores desempenharem esse trabalho. É importante que o professor possua conhecimento de métodos e técnicas adequadas para a realização de um trabalho sistemático e contínuo de acompanhamento ao desenvolvimento do aluno surdo.
}

Como forma de tentar combater o preconceito, foram criadas algumas normas e leis, além de cursos, para indivíduos com deficiência, entre eles, os surdos, de maneira a estimular o progresso profissional e a perda da dependência social. Na busca por esse impulso, fundou-se o Instituto Nacional de Educação de Surdos (INES), um órgão público para pensar a política de inclusão dos não ouvintes e prepará-los para o mercado de 
trabalho. Um dos pontos observados foi o reconhecimento da Língua Brasileira de Sinais (LIBRAS), fruto de movimento dos surdos. A ação levou em consideração o conhecimento da referida língua como um facilitador da comunicação entre pessoas com deficiência auditiva e não surdas.

As abordagens educacionais voltadas à educação dos surdos foram acompanhando as tendências mundiais por intermédio do Oralismo, da Comunicação Total e do Bilinguismo. Este aborda a educação às pessoas com problemas auditivos e se caracteriza pelo uso de duas línguas: a Língua de Sinais (materna para o surdo) deve ser trabalhada em primeiro lugar; a Língua Portuguesa, em segundo. Ambas diferem uma da outra e independem das línguas orais utilizadas, pois a primeira faz uso das mãos, do espaço, do movimento e do olhar. Nesse sentido, segundo Lacerda e Poletti (2007, p. 15) "O intérprete participa das atividades, procurando dar acesso aos conhecimentos e isso se faz com tradução, mas também com sugestões, exemplos e muitas outras formas de interação inerentes ao contato cotidiano com o aluno surdo em sala de aula".

\section{RELATOS E ANÁLISE DE EXPERIÊNCIAS COM DEFICIENTE AUDITIVO}

As evidências da presença de preconceitos de comunicação no meio escolar e também no mercado de trabalho preocupam o indivíduo surdo nos mais diversos setores conforme depoimentos obtidos neste estudo. Como exemplo, cita-se o caso de uma pessoa surda cuja família tem quatro portadores de deficiência auditiva e presencia essa realidade no dia a dia. O relato que segue foi transcrito mediante a autorização da família e a percepção da inclusão escolar demostra que:

A aceitação em sala de aula foi um tanto complicada, a novidade de um
aluno surdo foi uma surpresa para a professora e os colegas de sala de
aula, no começo foi difícil às vezes era complicado faze-lo ir para a
escola, por que tinha medo e tinha vergonha por ser surda, no começo
a comunicação com os colegas foi difícil até com a professora teve
certas barreiras a cruzar, levou algum tempo para a adaptação escolar,
cada dia era uma dificuldade, tanto na aprendizagem quanto na
socialização com a turma, era complicado a forma de aprender, pelo
fato de não ter um ensino correto a um surdo, o que seria a libras, onde
acabava tendo que recorrer aos meios normais de ensino da família, que
porem dificultava muito E assim foi até o ensino médio. Vários pontos
de dificuldade com o tempo foram superados, o mesmo aprendeu a se
comunicar através de "libras" caseiras com a família e alguns amigos
mais próximos da família, basicamente o ensino da comunicação do
surdo foi colocado em casa, até o ensino médio onde a sociedade já

Educação, Psicologia e Interfaces, Volume 4, Número 3, p. 1-11, Outubro/Dezembro, 2020.

ISSN: 2594-5343. DOI:https://doi.org/10.37444/issn-2594-5343.v4i3.325 
tinha avançado um pouco na educação e cada um tinha um pouco de conhecimento com a comunicação de Libras, em diante as coisas melhoraram um pouco a favor do surdo. Seu desenvolvimento escolar foi bom e a convivência com a turma foi excelente, onde acabou tendo amigos que até hoje o reconhecem e que o mais importante que não o tratou com descriminação e nem debochou por ser deficiente auditivo, a socialização com os amigos ajudou muito para que ele se incentivasse ainda mais aos estudos, concluindo o ensino médio não foi possível a realização da entrada no ensino superior.

Já quanto à percepção de inclusão no mercado de trabalho, o depoente reiterou que:

Com as grandes dificuldades e com os receios de tentar entrar em uma universidade para se capacitar na vida. O mesmo decidiu optar por outro meio de vida, onde acabou trabalhando para mercados de trabalho da família e de alguns amigos mais próximos, mais enfrentando grandes dificuldades de comunicação com o povo em geral, pelo fato de poucas pessoas terem conhecimento da língua de libras para se comunicarem com um surdo, muitas das vezes o mesmo era recusado em meios empresarias por portar uma deficiência, onde causou grande preconceito por ele ter essa deficiência. Em um dos poucos empregos que conseguiu foi bastante desafiador, onde a comunicação com os colegas de trabalho era péssima, a falta do ensino de Libras as demais pessoas não deficientes foram um tanto problemáticas para o avanço empresarial do surdo. Com as dificuldades que encontrava quando trabalhava resultou em uma decisão diferenciada, onde o mesmo optou a trabalhar para si mesmo, em uma borracharia, onde apenas a mãe e esposa o ajudam, ainda o preconceito é grande, e o olhar da sociedade ao surdo é apenas sendo incapaz, onde acaba fazendo com que o mesmo não consiga ter uma vida no mercado de trabalho digna como de outras pessoas. Ainda há muito para mudado para o surdo ser incluso no mercado de trabalho, onde necessita de ensino a todos pelo menos o básico de Libras, para deixar o ambiente favorável ao surdo e que o preconceito por acharem o deficiente incapaz de tudo acabe, assim teríamos um país digno para todas as pessoas perante qualquer situação ${ }^{1}$.

A inclusão do surdo no mercado de trabalho é um dos fatos que mais suscita preocupações, pois é perceptível a dificuldade de acessibilidade física e de meios de comunicação para que o indivíduo em questão necessita para desenvolver sua carreira, além de preconceitos existentes e desmerecimento em seu ambiente, consequentemente, influenciam as perspectivas dele conquistar um futuro promissor sem precisar viver com a ajuda total de suas famílias. A escola é o meio de acesso a educação e o conhecimento amplo da sociedade que a pessoa surda tem disponível.

Educação, Psicologia e Interfaces, Volume 4, Número 4, p. 1-11, Outubro/Dezembro, 2020.

ISSN: 2594-5343. DOI: https://doi.org/10.37444/issn-2594-5343.v4i3.325 
Entretanto, faz-se necessária a qualificação dos professores para que estes possam capacitar o surdo e incentivá-lo a buscar uma carreira e ter um futuro digno, mostrando que a educação tem o potencial de desenvolver atividades que contemplem suas limitações. Como foi demonstrado, até no ambiente escolar, os surdos sofrem preconceitos. O fato é que alguns docentes e colegas, muitas vezes, acabam desmerecendo o (a) estudante em função de sua deficiência auditiva, com ocorrência de "bullying", propiciando-lhe o isolamento, além de impor limitações às suas pretensões profissionais.

A reflexão sobre a inclusão social deve abranger todos os âmbitos sociais, criando a cultura da tolerância por meio do aprendizado e convívio com as diferenças, motivando quem sofre o preconceito a encarar a sociedade e conquistar espaço no mercado de trabalho. Com isso, contribui, de maneira significativa, para reduzir o número de exclusão de pessoas com deficiência do mercado de trabalho e melhorar a sua qualidade de vida. Dessa forma, é possível praticar a igualdade de oportunidades, tornando a sociedade mais justa e sem preconceito.

\section{CONSIDERAÇÕES FINAIS}

O preconceito e o mito da incapacidade da pessoa com deficiência, embora combatido em diversos setores, ainda permanece na cultura brasileira, limitando a mentalidade do mercadode trabalho na hora da contratação de um indivíduo pertencente a esse grupo. Em efeito, a sociedade ainda não olha o sujeito portador de alguma deficiência como um ser humano comum, fato presente na realidade de muitas pessoas que se deparam com alguma incapacidade.

É oportuno lembrar que o mercado de trabalho tem o dever de incluir pessoas deficientes; porém, na prática, isso é raro acontecer mesmo com os grandes avanços tecnológicos disponíveis para capacitá-las profissionalmente. Além de promover a igualdade, concederia uma chance ao surdo conquistar sua independência financeira. Dessa forma, o estudo propõe a realização de novos trabalhos acerca do tema para que seja difundido na sociedade, bem como conscientizá-la do problema. Com isso, esperase contribuir para minimizar essas dificuldades e diminuir os preconceitos enfrentados por essa parcela da população. De fato, uma das grandes questões que merece reflexão é detalhar esse paradigma histórico de barreiras na vida profissional das pessoas surdas que, ao longo dos anos, vêm sofrendo com as restrições e impossibilidades de inclusão nos 
diferentes campos da sociedade mesmo amparadas por uma legislação considerada importante.

Em feito, a Lei tem sido insuficiente para convencer muitas empresas a incluírem em seus quadros pessoas com algum tipo de deficiência, como no caso dos surdos, a quem não são garantidas uma qualidade e consistência no campo de trabalho. Por outro lado, é necessário que haja espaços que promovam constantemente a formação de mais profissionais nesse campo, informações de qualidade aos gestores, orientação aos colaboradores, investimentos em acessibilidade e acompanhamento dos incluídos. Isso é fundamental para que o mercado consiga se apresentar de forma inclusiva perante a sociedade.

\section{Notas de rodapé}

${ }^{1}$ Relato de Maria Aparecida: com a intenção de resguardar a identidade dos sujeitos optamos em estabelecer nomes fictícios.

\section{REFERÊNCIAS BIBLIOGRÁFICAS}

BRASIL. A inclusão de pessoas com deficiência no mercado de trabalho. 2. ed. Brasília: MTE/SIT, 2007.

BRASIL. Decreto $\mathrm{n}^{\circ}$ 3.956, de 8 de outubro de 2001. Dispõe sobre a Convenção Interamericana para a Eliminação de Todas as Formas de Discriminação contra as Pessoas Portadoras de Deficiência. Disponível em: <http://www.planalto.gov.br/ccivil_03/decreto/2001/d3956.htm>. Acesso em: 24 de set. de 2019.

BRASIL. Lei no 10.436 de 24 de abril de 2002. Dispõe sobre a Língua Brasileira de Sinais - LIBRAS e dá outras providências. Disponível em: <http://www.planalto.gov.br/ccivil_03/leis/2002/110436.htm>. Acesso em: 14 ago. 2019.

BRASIL. Lei ${ }^{\circ} 8.213$ de 24 de julho de 1991. Lei de Cotas. Disponível em: <http://www.planalto.gov.br/ccivil_03/leis/L8213cons.htm>. Acesso em: 24 set. 2018.

FERREIRA, Cristiane Bonifácio et al. A inclusão do aluno surdo na rede regular de ensino. Revista Mundo \& Letras, São Paulo, v. 1, n. 1, p. 71-82, 2010.

FONSECA, Claudio. O que é deficiência auditiva? Direito de Ouvir, 2017. Disponível em: 〈https://www.direitodeouvir.com.br/blog/deficiencia-auditiva>. Acesso em: 10 jun. 2020 . 
LACERDA, Cristina; POLETTI, Juliana. A escola inclusiva para surdos: a situação singular do intérprete de língua de sinais. In: REUNIÃO ANUAL DA ANPED, 27., 21 a 24 nov. 2007. Anais... Caxambu/MG: Anped, 2007.17p.

SILVEIRA, Tatiana dos Santos; NASCIMENTO, Luciana Monteiro. Caderno de Estudos Educação Inclusiva. Indaial: Uniasselvi, 2013.

VILELA, Flávia. IBGE: 6,2\%da população têm algum tipo de deficiência. Agência Brasil, 2015. Disponível em: <http://agenciabrasil.ebc.com.br/geral/noticia/201508/ibge-62-da-populacao-tem-algum-tipo-de-deficiencia>. Acesso em: 26 jun. 2019.

\section{Credenciais da/os autora/es}

ANTUNES, Maria de Fátima Nunes. Docente na Secretaria de Educação do Estado do Mato Grosso- SEDUC/MT. Graduada em Licenciatura Plena em Pedagogia (UNIFLOR), Matemática (UNIASSELVI) especialista em Educação Especial e Psicopedagogia e Libras (Prominas). Mestra em Ensino de Ciências Exatas (Univates). E-mail: mariadefatimanunesantunes@gmail.com

ARCARI, Inedio. Docente da Universidade do Estado de Mato Grosso- UNEMAT/MT. Mestre em Matemática (UNICAMP), Doutor em Engenharia Elétrica (UNESP). E-mail: inediobbg@unemat.br

PURIFICAÇÃO, Marcelo Máximo. Docente Adjunto no Centro Universitário de Mineiros (UNIFIMES), Brasil. Graduação em Matemática (PUC). Doutor em Ciências da Religião (PUC). E-mail: marcelo.ueg@gmail.com

\section{Endereço para correspondência:}

ANTUNES, Maria de Fátima Nunes. Rua dos Cravos, 1415B, Bairro Jardim das Oliveiras, 78552325, Sinop/MT

\section{Como citar este artigo (Formato ABNT):}

ANTUNES, Maria de Fátima Nunes; ARCARI, Inedio; PURIFICAÇÃO, Marcelo Maximo. Reflexão sobre a inclusão do surdo no mercado de trabalho. Educação, Psicologia e Interfaces, v. 4, n. 4, p. 1-11, 2020. Doi: https://doi.org/10.37444/issn-25945343.v4i3.325

Recebido: 07/04/2020.

Aceito: 20/05/2020. 